\title{
CYP3A5 polymorphisms and their effects on tacrolimus exposure in an ethnically diverse South African renal transplant population
}

\author{
W K Muller, ${ }^{1}$ MB ChB, FCP; C Dandara, ${ }^{2,3}$ BSc, BSc Hons, PhD; K Manning, ${ }^{4}$ BSc (Diet), MSc (Med), MPH (Epidemiol); \\ D Mhandire, ${ }^{2,3}$ BMLSC, MPhil; J Ensor, ${ }^{1,5}$ MB ChB, FCP, Cert Nephrology (SA); Z Barday, ${ }^{5}$ MB ChB, FCP, Cert Nephrology (SA); \\ R Freercks, ${ }^{1,5} \mathrm{MB}$ ChB, FCP, Cert Nephrology (SA), MPhil, FRCP \\ ${ }^{1}$ Division of Nephrology, Department of Medicine, Livingstone Hospital and Faculty of Health Sciences, Walter Sisulu University, Port Elizabeth, \\ South Africa \\ ${ }^{2}$ Pharmacogenomics and Drug Metabolism Group, Division of Human Genetics, Department of Pathology, Faculty of Health Sciences, University \\ of Cape Town, South Africa \\ ${ }^{3}$ Institute of Infectious Diseases and Molecular Medicine, University of Cape Town, South Africa \\ ${ }^{4}$ Department of Medicine, Groote Schuur Hospital and Faculty of Health Sciences, University of Cape Town, South Africa \\ ${ }^{5}$ Division of Nephrology and Hypertension, Department of Medicine, Groote Schuur Hospital and Faculty of Health Sciences, University of Cape \\ Town, South Africa
}

Corresponding author: W K Muller (warrenmuller10@gmail.com)

Background. Tacrolimus forms the cornerstone for immunosuppression in solid-organ transplantation. It has a narrow therapeutic window with wide inter- and intra-patient variability (IPV). Cytochrome P-450 3A5 (CYP3A5) is the main enzyme involved in tacrolimus metabolism, and rs776746A $>\mathrm{G}$ is the most frequently studied polymorphism in the CYP3A5 gene. The rs776746A $>\mathrm{G}$ (i.e. CYP3A5*3) single-nucleotide polymorphism in CYP3A5 alters tacrolimus predose trough concentration $\left(\mathrm{C}_{0}\right)$ and may also affect IPV, which may lead to immune- and/or drug-mediated allograft injury. CYP $3 A 5^{\star} 3$ may result in absent $\left({ }^{*} 3 /{ }^{*} 3\right)$, partial $\left({ }^{*} 1 /{ }^{*} 3\right)$ or normal $\left({ }^{*} 1 /{ }^{*} 1\right) C Y P 3 A 5$ expression. The effect of CYP $3 A 5^{\star} 3$ on tacrolimus exposure and variability has not been examined in South African (SA) transplant recipients.

Objectives. To determine the frequencies and effect of CYP3A5 and adenosine triphosphate-binding cassette subfamily B member 1 $(A B C B 1)$ polymorphisms on tacrolimus $\mathrm{C}_{0}$ /dose ratios in different ethnic groups attending a tertiary renal transplant clinic in $\mathrm{SA}$, and other factors that may explain inter- and IPV in tacrolimus $\mathrm{C}_{0}$.

Methods. All consenting stable renal transplant recipients on tacrolimus at the Livingstone Hospital Renal Unit in Port Elizabeth, SA, were included. Tacrolimus concentrations were obtained using a microparticle enzyme immunoassay method (ARCHITECT analyser, Abbott Laboratories). Polymerase chain reaction/restriction fragment length polymorphism was used to genotype for $C Y P 3 A 5^{\star} 3$ and ${ }^{\star} 6$ allelic variants. Results. There were 43 participants (35\% black African, $44 \%$ mixed ancestry and $21 \%$ white), with a mean age of 44.5 years, median duration post-transplant of 47 months and median (interquartile range) creatinine and estimated glomerular filtration rate levels of $118(92-140) \mu \mathrm{mol} / \mathrm{L}$ and $62(49-76) \mathrm{mL} / \mathrm{min}$ at study inclusion. The mean tacrolimus $\mathrm{C}_{0}$ in the study was $6.7 \mathrm{ng} / \mathrm{mL}$, with no difference across the different ethnic groups. However, the mean total daily dose of tacrolimus required was $9.1 \mathrm{mg}(0.12 \mathrm{mg} / \mathrm{kg}), 7.2 \mathrm{mg}(0.09 \mathrm{mg} / \mathrm{kg})$ and $4.3 \mathrm{mg}(0.06 \mathrm{mg} / \mathrm{kg})$ in black, mixed-ancestry and white patients, respectively $(p=0.017)$. The frequencies for CYP3A5 expressors (i.e. CYP $3 A 5^{*} 1 /{ }^{*} 1+C Y P 3 A 5^{*} 1 /{ }^{*} 3$ genotypes) were $72 \%, 100 \%, 76 \%$ and $12 \%$ for all patients combined and black, mixed-ancestry and white patients, respectively. The frequencies for CYP3A5 non-expressors (i.e. CYP3A $5^{\star} 3 /{ }^{\star} 3$ genotypes) were $0 \%, 24 \%$ and $88 \%$ among the black, mixed-ancestry and white patients, respectively. None of the patients carried the $C Y P 3 A 5^{\star} 6$ allele. $C Y P 3 A 5^{*} 1 /{ }^{*} 1$ and $C Y P 3 A 5^{\star} 1 /{ }^{*} 3$ genotype carriers required a two-fold increase in dose compared with the non-expressor genotype carriers, $C Y P 3 A 5^{*} 3{ }^{*} 3(p<0.05)$. CYP $3 A 5^{*} 3 /{ }^{*} 3$ carriers also demonstrated higher IPV than $C Y P 3 A 5^{*} 1 /{ }^{*} 1$ and ${ }^{*} 1 /{ }^{*} 3$ carriers $(18.1 \%$ v. $14.2 \% ; p=0.125)$.

Conclusions. Compared with global transplant populations, SA renal transplant recipients demonstrated a very high rate of $C Y P 3 A 5$ expression, with a significant impact on tacrolimus pharmacokinetics. Genetic variation in CYP3A5 expression affects tacrolimus dosing requirements, and knowing the CYP3A5 genotype of transplant patients may allow better dose prediction compared with current standard dosing recommendations in a multi-ethnic population. Overall, black African patients required higher doses of tacrolimus than their white counterparts. While further prospective studies are needed to better evaluate dosing algorithms, it would appear that the starting dose of tacrolimus should be higher in black and mixed-race patients.

S Afr Med J 2020;110(2):159-166. https://doi.org/10.7196/SAMJ.2020.v110i2.13969

Tacrolimus is a calcineurin inhibitor frequently used in transplantation to prevent allograft rejection. ${ }^{[1,2]}$ Its use has been associated with improved graft survival, and it currently forms the cornerstone of immunosuppressive therapy in solid-organ transplantation. ${ }^{[3]}$ There is a shortage of donors, especially cadaveric donors, on an international and local level. Maintaining graft function is therefore of the utmost importance to protect a limited resource in medicine. ${ }^{[4,5]}$

Tacrolimus has a narrow therapeutic window and wide pharmacokinetic variability in transplant recipients. ${ }^{[1,6,7]}$ In clinical practice, this translates into marked inter- and intra-patient variability (IPV) in measured tacrolimus predose trough concentrations $\left(\mathrm{C}_{0}\right)$, 
which makes selection of the appropriate dose difficult for transplant physicians. ${ }^{[1]}$ Tacrolimus IPV, which is defined as fluctuations of measured tacrolimus $\mathrm{C}_{0}$ in an individual over a given period of time, is an independent predictor for worsening graft function. ${ }^{[8,9]}$ Variability in tacrolimus $\mathrm{C}_{0}$ may result in subtherapeutic levels, leading to inferior graft outcomes from immune-mediated allograft injury with allograft rejection. ${ }^{[10]}$ On the other hand, high tacrolimus $\mathrm{C}_{0}$ may also lead to an adverse side-effect profile and renal toxicity. ${ }^{[11,12]}$

While various non-pharmacogenetic factors such as poor adherence, high-fat meals, grapefruit intake, drug-drug interactions and circadian rhythms may explain some of this variability, ${ }^{[1,13]}$ much attention has been given in the past two decades to pharmacogenomics and the cytochrome pathway. ${ }^{[14]}$ Tacrolimus is predominantly a substrate for metabolism by cytochrome P-450 3A5 (CYP3A5) and is dependent on cellular transport by P-glycoprotein (P-gp), coded for by the adenosine triphosphate (ATP)-binding cassette subfamily B member $1(A B C B 1)$ gene. Single-nucleotide polymorphisms (SNPs) in the CYP3A5, CYP3A4 and $A B C B 1$ genes affect tacrolimus $\mathrm{C}_{0}$ and the dose required through variability in metabolism and absorption, respectively. ${ }^{[15,16]}$

The CYP450 enzymes are membrane-bound proteins found in the endoplasmic reticulum that facilitate metabolism of a wide variety of drugs. ${ }^{[1]}$ CYP3A5 is the major enzyme involved in the metabolism of tacrolimus, while CYP3A4 plays a minor role. ${ }^{[17,18]}$ The rs776746A $>\mathrm{G}$ (i.e. CYP $3 A 5^{\star} 3$ ) SNP in CYP3A5 abolishes CYP3A5 enzyme activity and has been reported to alter tacrolimus $\mathrm{C}_{0}$. CYP3A5 may result in absent $\left({ }^{*} 3 /{ }^{*} 3\right)$, partial $\left({ }^{*} 1 /{ }^{*}\right)$ or normal $\left({ }^{*} 1 /{ }^{*} 1\right)$ CYP3A5 expression. ${ }^{[15-17]} \mathrm{A}$ second allele $\left(C Y P 3 A 5^{\star} 6\right)$ resulting from a splicing variant at $14690 \mathrm{G}>\mathrm{A}$ also produces a non-functional CYP3A5 enzyme. ${ }^{[1,18]}$

Transplant recipients with normal or partial expression of CYP3A5 require higher tacrolimus doses than non-expressors to achieve similar therapeutic tacrolimus $\mathrm{C}_{0}{ }^{[15,17,19]}$ Other enzymes may also influence inter- and IPV in tacrolimus dosing, namely P450 oxidoreductase (POR), nuclear receptor perioxisome proliferatoractivated receptor alpha (PPAR- $\alpha$ ) and CYP2C8. ${ }^{[1,19]}$

The $A B C B 1$ gene encodes P-gp, which functions as an ATPdependent efflux pump that protects intestinal cells from harmful substances. The absorption of certain drugs from the gut is therefore inversely proportional to P-gp expression. Polymorphisms in $A B C B 1$ alter expression of $\mathrm{P}$-gp, which in turn can affect tacrolimus $\mathrm{C}_{0}$ by altering drug absorption from the intestine. An SNP in exon 26 (3435 $\mathrm{C}>\mathrm{T}$ ) in the $A B C B 1$ gene has been widely studied for its effects on many drugs. ${ }^{[1,16,20]}$ The $A B C B 13435 \mathrm{~T}$ allele is associated with reduced expression of $A B C B 1 .{ }^{[20,21]}$ The role of SNPs in $A B C B 1$ on tacrolimus $\mathrm{C}_{0}$ and dosing is currently controversial, and several studies have shown conflicting results pointing towards a minor role. ${ }^{[15,19,22]}$

\section{Objectives}

The frequencies of SNPs of CYP3A5 and $A B C B 1$ and their effect on tacrolimus $\mathrm{C}_{0} /$ dose ratios have been described internationally, but not in South African (SA) renal transplant recipients. ${ }^{[15,23-25]}$ We therefore set out to determine the frequencies and effect of CYP3A5 and $A B C B 1$ polymorphisms on tacrolimus $\mathrm{C}_{0} /$ dose ratios in different ethnic groups attending a tertiary renal transplant clinic at Livingstone Hospital, Port Elizabeth, SA, and to determine other factors that may explain inter- and IPV in tacrolimus $\mathrm{C}_{0}$.

\section{Methods}

Study participants and sample collection

A cohort of stable renal transplant recipients at least 12 months post transplant was invited to participate in the study. Stable was defined as having had no major intercurrent illness during the preceding 12 months. Ethics approval for genetic testing was obtained from the Walter Sisulu University Ethics Committee (ref. no. 017/2016). The study was a retrospective cohort study, and information was obtained from four quarterly periods prior to the inclusion date. Data were collected on relevant demographic and clinical measures. Self-reported ethnicity was included in our data collection tool and categorised as black African, mixed ancestry and white.

All consenting patients aged $>18$ years who were using tacrolimus as part of their immunosuppression were included. Five millilitres of venous whole blood was taken in ethylenediaminetetra-acetic acidcontaining blood tubes and stored at $-20^{\circ} \mathrm{C}$. Repeated tacrolimus $\mathrm{C}_{0}$ and dosages were obtained retrospectively from case notes. Data collected included body weight, age, level of education, type of immunosuppression used, perceived medication adherence, type of transplant, months post-transplant, ethnicity (self-reported) and the aetiology of chronic kidney disease. Five recipients who were positive for HIV were excluded from the study because of potential drug interactions. Two other patients were excluded because they were also using medications known to affect tacrolimus $\mathrm{C}_{0}$, such as antifungal agents, rifampicin, verapamil, macrolide antibiotics and antiepileptics.

\section{Analytical methods}

Tacrolimus $\mathrm{C}_{0}(\mathrm{ng} / \mathrm{mL})$ was obtained by means of a microparticle enzyme immunoassay method using the ARCHITECT analyser (Abbott Laboratories, USA). DNA was extracted using the QIAamp DNA Mini Kit (Qiagen, Germany), following the manufacturer's instructions. Polymerase chain reaction (PCR)-restriction fragment length polymorphism (RFLP) was used to genotype $C Y P 3 A 5^{*} 3$ and ${ }^{*} 6$ and $A B C B 1$. Each PCR reaction contained the following reagents: $0.40 \mu \mathrm{M}$ of each of the forward and reverse primers (Inqaba Biotechnical Industries, SA), 100 ng of genomic DNA, $1 \times$ Green GoTaq Flexi Reaction Buffer (Promega, USA), $0.2 \mathrm{mM}$ deoxyribonucleotide triphosphate (Promega), $2.5 \mathrm{mM}$ magnesium chloride (Promega) and 0.5 U GoTaq Flexi DNA Polymerase (Promega), and was made up to a volume of $25 \mu \mathrm{L}$ with sterile deionised water.

PCR and RFLP conditions are summarised in Table 1.

\section{Statistical analysis}

Categorical variables were summarised as frequencies and percentages. Continuous variables were summarised as means and standard deviations (SDs). Student's $t$-test or analysis of variance was used to compare continuous tacrolimus measures (dosage, level and $\mathrm{C}_{0}$ dose $/ \mathrm{kg}$ ) variables between two groups and three groups, respectively. Linear mixed-effects models were used to analyse the change in repeated variables (tacrolimus dose, $\mathrm{C}_{0} /$ dose, creatinine and estimated glomerular filtration rate (eGFR)) associated with increasing time. IPV in tacrolimus was expressed as a coefficient of variation using the following formula: $\mathrm{CV} \%=(\sigma / \mu) \times 100$

A $p$-value $<0.05$ was considered statistically significant. Statistical analysis was carried out using Stata statistical software, version 15.1 (StataCorp, USA).

\section{Results \\ Study participants}

There were 43 study participants, of whom 18 (42\%) received a kidney from a related living donor, with the rest receiving cadaveric transplants. All the patients were stable during the study period with no major illnesses reported. Baseline demographics and clinical characteristics are shown in Table 2. All the participants were non- 


\begin{tabular}{|c|c|c|c|c|}
\hline SNP & Primer $\left(5^{\prime}-3^{\prime}\right)$ & $T_{a}$, ext & Thermal cycling conditions & Restriction enzyme \\
\hline$C Y P 3 A 5^{\star} 3$ & $\begin{array}{l}\text { F: CATCAGTTAGTAGACAGATGA } \\
\text { R: GGTCCAAACAGGGAAGAAATA }\end{array}$ & $51^{\circ} \mathrm{C}, 30 \mathrm{~s}$ & $\begin{array}{l}94^{\circ} \mathrm{C}, 3 \mathrm{~min} \\
94^{\circ} \mathrm{C}, 30 \mathrm{~s} \\
51^{\circ} \mathrm{C}, 30 \mathrm{~s} \\
72^{\circ} \mathrm{C}, 30 \mathrm{~s} \\
72^{\circ} \mathrm{C}, 10 \mathrm{~min}\end{array}$ & $\begin{array}{l}\text { SspI, } \\
12-16 \mathrm{~h}\end{array}$ \\
\hline CYP $3 A 5^{\star} 6$ & $\begin{array}{l}\text { F: GTGGGGTGTTGAZAGCTAAAG } \\
\text { R: TGGAAGATGATTCAGCAGATAGT }\end{array}$ & $55^{\circ} \mathrm{C}, 30 \mathrm{~s}$ & $\begin{array}{l}94^{\circ} \mathrm{C}, 3 \mathrm{~min} \\
94^{\circ} \mathrm{C}, 30 \mathrm{~s} \\
55^{\circ} \mathrm{C}, 30 \mathrm{~s} \\
72^{\circ} \mathrm{C}, 1 \mathrm{~min} \\
72^{\circ} \mathrm{C}, 10 \mathrm{~min}\end{array}$ & $\begin{array}{l}\text { DdeI, } \\
12-16 \mathrm{~h}\end{array}$ \\
\hline$A B C B 1(1236 \mathrm{C}>\mathrm{T})$ & $\begin{array}{l}\text { F: ACTCTTGTTTTCAGCTGCTTG } \\
\text { R: GAGTCACTGCCTAATGTAAGTCTCT }\end{array}$ & $54^{\circ} \mathrm{C}, 30 \mathrm{~s}$ & $\begin{array}{l}94^{\circ} \mathrm{C}, 3 \mathrm{~min} \\
94^{\circ} \mathrm{C}, 30 \mathrm{~s} \\
54^{\circ} \mathrm{C}, 30 \mathrm{~s} \\
72^{\circ} \mathrm{C}, 50 \mathrm{~s} \\
72^{\circ} \mathrm{C}, 10 \mathrm{~min}\end{array}$ & $\begin{array}{l}\text { MboI, } \\
12-16 \mathrm{~h}\end{array}$ \\
\hline
\end{tabular}

Table 2. Baseline demographics and clinical characteristics of the population studied $(N=43)$

\begin{tabular}{|c|c|}
\hline Characteristic & \\
\hline Age (years), mean (SD) & $45(12)$ \\
\hline Males, $n(\%)$ & $25(58)$ \\
\hline Cadaveric transplants, $n(\%)$ & $25(58)$ \\
\hline Living related donor transplants, $n(\%)$ & $18(42)$ \\
\hline Months post transplant, median (IQR) & $47(24-110)$ \\
\hline \multicolumn{2}{|l|}{ Indication for transplant, $n(\%)$} \\
\hline Hypertension & $23(54)$ \\
\hline ADPKD & $6(14)$ \\
\hline Glomerulonephritis & $5(12)$ \\
\hline CAKUT & $4(9)$ \\
\hline Diabetic nephropathy & $1(2)$ \\
\hline Other* & $4(9)$ \\
\hline Weight $(\mathrm{kg})$, mean $(\mathrm{SD})$ & $75(14)$ \\
\hline \multicolumn{2}{|l|}{ Ethnicity, $n(\%)$} \\
\hline Black African & $15(35)$ \\
\hline Mixed ancestry & $19(44)$ \\
\hline White & $9(21)$ \\
\hline HIV status negative, $n(\%)$ & $43(100)$ \\
\hline \multicolumn{2}{|l|}{ Baseline immunosuppression, $n(\%)$} \\
\hline Prednisone & $43(100)$ \\
\hline Azathioprine & $10(23)$ \\
\hline MMF & $30(70)$ \\
\hline Tacrolimus & $43(100)$ \\
\hline NODAT, $n(\%)$ & $13(30)$ \\
\hline Males & $10(77)$ \\
\hline Females & $3(23)$ \\
\hline $\begin{array}{l}\mathrm{SD}=\text { standard deviation; } \mathrm{IQR}=\text { interquartile range; } \\
\text { polycystic kidney disease; } \mathrm{CAKUT}=\text { congenital abno } \\
\text { tract; } \mathrm{MMF}=\text { mycophenolate mofetil; NODAT }=\text { new } \\
{ }^{*} \text { Includes acute tubular necrosis, urological strictures }\end{array}$ & $\begin{array}{l}\text { mal dominant } \\
\text { kidney and urinary } \\
\text { after transplantation } \\
\text { auses. }\end{array}$ \\
\hline
\end{tabular}

smokers. Self-reported ethnic groups were black African $(n=15)$, mixed ancestry $(n=19)$ and white $(n=9)$.

New-onset diabetes after transplantation (NODAT) was more common in males, with a prevalence of $10 / 13$ (77\%) v. $23 \%$ in females. Patients with NODAT had a higher mean serum creatinine level than those without NODAT $(132 \mu \mathrm{mol} / \mathrm{L}$ v. $117 \mu \mathrm{mol} / \mathrm{L} ; p=0.253)$ and were more likely to have autosomal dominant polycystic kidney disease (ADPKD), with NODAT developing in 67\% of those with ADPKD v. $24 \%$ of the others.

\section{Indication for transplantation}

Hypertension (54\%) was the leading indication for transplantation, followed by ADPKD (14\%), glomerulonephritis (12\%) and congenital abnormalities of the kidney and urinary tract (9\%). Other causes included acute tubular necrosis, urological strictures and unknown aetiologies.

\section{Tacrolimus dose and $\mathrm{C}_{0}$ over the study period}

Table 3 shows the mean tacrolimus $\mathrm{C}_{0}$ and dosing requirements during the study period. Mean tacrolimus $\mathrm{C}_{0}(6.7 \mathrm{ng} / \mathrm{mL})$ and dose $(7.3 \mathrm{mg} / \mathrm{d})$ did not change significantly over the study period. The mean (SD) creatinine level was $121.5(39) \mu \mathrm{mol} / \mathrm{L}$, with an absolute increase over the study period of $8.9 \mu \mathrm{mol} / \mathrm{L}(p=0.004)$. The mean (SD) eGFR was $62(18) \mathrm{mL} / \mathrm{min} / 1.72 \mathrm{~m}^{2}$ and remained unchanged over the study period $(p=0.616)$.

Table 4 shows the frequency and distribution of genotypes across ethnic groups. Among those who could be genotyped (39 of the 43 participants), homozygous $C Y P 3 A 5^{*} 1 /{ }^{*} 1$ frequency was highest in black Africans (64\%), followed by patients of mixed ancestry (41\%), while the genotype was not observed among white patients; the inverse was true for the non-expressor $C Y P 3 A 5^{*} 3 /{ }^{*} 3$ genotype, with frequencies of $0 \%, 24 \%$ and $88 \%$ among black Africans, patients of mixed ancestry and whites, respectively. Overall, $72 \%$ of the study population were CYP $3 A 5$ expressors $\left(C Y P 3 A 5^{*} 1 /{ }^{*} 1+{ }^{*} 1 /{ }^{*} 3\right)$. CYP $3 A 5^{\star} 6$ was not observed in the study population.

The $A B C B 13435 \mathrm{C}>\mathrm{T}$ SNP genotypes also showed differences among the different race groups, with the exception that the T/T genotype appeared less frequently in black Africans (0\%) than in patients of mixed ancestry (11\%) and whites (33\%). Two participants could not have the $A B C B 1$ gene typed.

\section{Effect of ethnicity on tacrolimus $\mathrm{C}_{0}$ and dose}

The mean (SD) tacrolimus dose for each ethnic group was as follows: black African 9.1 (4.2) mg, mixed ancestry 7.2 (4.1) mg, and white 4.3 (2.2) $\mathrm{mg}$ (Table 5). This translates into a weight-based 


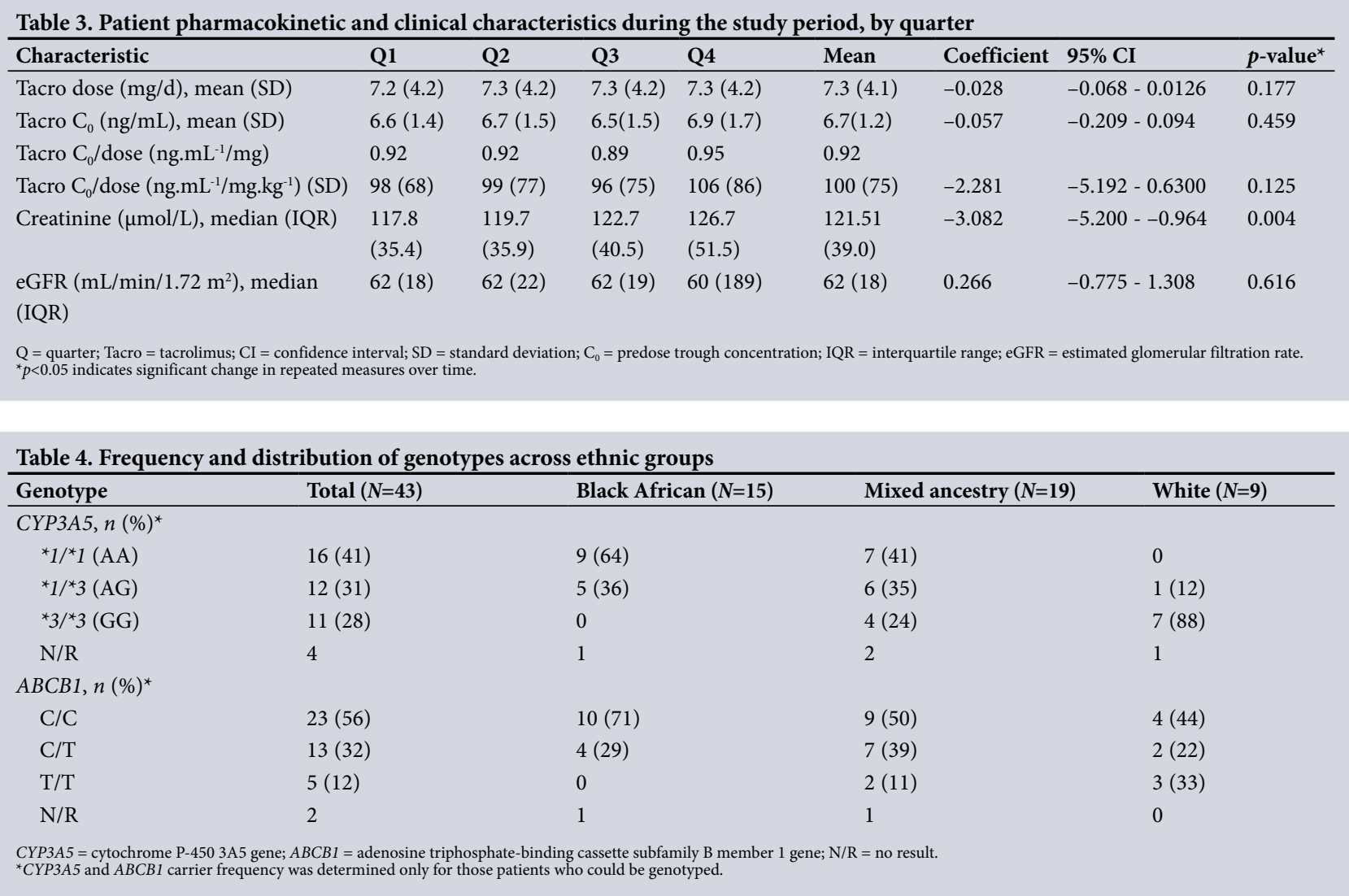

\begin{tabular}{|c|c|c|c|c|c|c|c|}
\hline Clinical characteristics & Race & Q1 & Q2 & Q3 & Q4 & $p$-value & Mean (SD) \\
\hline \multirow[t]{4}{*}{ Tacrolimus dose (mg), mean (SD) } & Black African & $8.9(3.6)$ & $9.2(4.2)$ & $9.2(4.2)$ & $9.2(4.2)$ & 0.171 & $9.1(4.1)$ \\
\hline & Mixed ancestry & $7.2(4.1)$ & $7.2(4.1)$ & $7.2(4.1)$ & $7.2(4.1)$ & * & $7.2(4.1)$ \\
\hline & White & $4.3(2.2)$ & $4.3(2.2)$ & $4.3(2.2)$ & $4.3(2.2)$ & * & $4.3(2.2)$ \\
\hline & $p$-value & 0.017 & 0.017 & 0.017 & 0.016 & & 0.017 \\
\hline \multirow{4}{*}{ Tacrolimus $\mathrm{C}_{0}(\mathrm{ng} / \mathrm{mL})$, mean $(\mathrm{SD})$} & Black African & $7.0(1.8)$ & $6.8(1.6)$ & $7.1(1.4)$ & $6.8(1.5)$ & 0.998 & $6.9(1.6)$ \\
\hline & Mixed ancestry & $6.7(1.5)$ & $6.3(1.5)$ & $6.5(1.6)$ & $6.5(1.4)$ & 0.708 & $6.5(1.5)$ \\
\hline & White & $7.1(2.2)$ & $6.1(1.3)$ & $6.1(1.6)$ & $6.4(1.3)$ & 0.376 & $6.5(1.6)$ \\
\hline & $p$-value & 0.890 & 0.524 & 0.300 & 0.770 & & 0.519 \\
\hline
\end{tabular}

Table 6. Effects of polymorphisms in CYP3A5 and $A B C B 1$ on tacrolimus $\mathrm{C}_{0}$

\begin{tabular}{|c|c|c|c|c|c|c|c|}
\hline \multirow[b]{2}{*}{ Genotype } & \multirow[b]{2}{*}{ Allelic status } & \multicolumn{5}{|c|}{ Tacrolimus $\mathrm{C}_{0}(\mathrm{ng} / \mathrm{mL})$, mean $(\mathrm{SD})$} & \multirow[b]{2}{*}{$p$-value } \\
\hline & & Q1 & Q2 & Q3 & Q4 & Mean & \\
\hline$C Y P 3 A 5^{\star} 1{ }^{\star} 1$ & $\mathrm{~A} / \mathrm{A}$ & $6.3(0.8)$ & $6.5(1.7)$ & $6.5(1.7)$ & $6.53(1.5)$ & $6.5(1.3)$ & 0.783 \\
\hline$C Y P 3 A 5^{*} 11^{*} 3$ & $\mathrm{G} / \mathrm{A}$ & $7.0(1.5)$ & $6.8(1.6)$ & $6.5(1.2)$ & $7.3(2.1)$ & $6.9(1.6)$ & 0.669 \\
\hline$C Y P 3 A 5^{*} 3{ }^{*} 3$ & $\mathrm{G} / \mathrm{G}$ & $6.2(1.2)$ & $6.3(1.4)$ & $6.2(1.3)$ & $6.7(1.4)$ & $6.4(1.3)$ & 0.263 \\
\hline \multirow[t]{3}{*}{$A B C B 1$} & $\mathrm{C} / \mathrm{C}$ & $6.5(1.1)$ & $6.5(1.4)$ & $6.6(1.6)$ & $7.0(1.7)$ & $6.7(1.4)$ & 0.181 \\
\hline & $\mathrm{C} / \mathrm{T}$ & $6.6(1.6)$ & $6.6(1.3)$ & $5.9(1.1)$ & $6.9(1.9)$ & $6.5(1.5)$ & 0.877 \\
\hline & $\mathrm{T} / \mathrm{T}$ & $7.5(2.0)$ & $7.7(2.7)$ & $7.3(1.6)$ & $6.7(1.6)$ & $7.3(2.0)$ & 0.297 \\
\hline
\end{tabular}

dose for black, mixed-ancestry and white study participants of $0.12,0.09$ and $0.06 \mathrm{mg} / \mathrm{kg}$, respectively, which differed significantly between ethnic groups $(p=0.017)$. Overall, there was no significant change in tacrolimus $\mathrm{C}_{0}$ over time when observed in each ethnic group.

\section{Effect of genotype on tacrolimus $\mathrm{C}_{\mathbf{0}}$}

Table 6 shows the effect of CYP3A5 and ABCB1 SNPs on tacrolimus $\mathrm{C}_{0}$ over the four quarters during the study period. Overall, there was no significant change in tacrolimus $\mathrm{C}_{0}$ over time when analysed per genotype. 


\section{Effect of genotype on tacrolimus dose requirements}

The distribution of $C Y P 3 A 5$ expressor status (i.e. CYP $3 A 5^{\star} 1 /{ }^{*} 1+{ }^{*} 1 /{ }^{*} 3$ ) in patients who could be genotyped was $100 \%, 75 \%$ and $12.5 \%$ among black African, mixed-ancestry and white participants, respectively. $C Y P 3 A 5^{*} 1{ }^{*} 1$ and $C Y P 3 A 5^{*} 1{ }^{*} 3$ genotypes were associated with a twofold increase in required tacrolimus dose $(p<0.05)$. The mean (SD) total daily dose per genotype was $9(0.12) \mathrm{mg} / \mathrm{kg}, 5(0.07) \mathrm{mg} / \mathrm{kg}$ and $3(0.04)$ $\mathrm{mg} / \mathrm{kg}$ for $C Y P 3 A 5^{*} 1 /{ }^{*} 1,{ }^{*} 1 /{ }^{*} 3$ and ${ }^{*} 3 /{ }^{*} 3$, respectively.

CYP3A5 genotypes had mean (SD) $\mathrm{C}_{0} /$ dose ratios of 54 (16), 95 (57) and 170 (94) for $C Y P 3 A 5^{\star} 1 /{ }^{*} 1,{ }^{*} 1 /{ }^{*} 3$ and ${ }^{\star} 3 /{ }^{*} 3$, respectively $(p<0.001)$. The $\mathrm{C}_{0} /$ dose ratio per CYP3A5 genotype over time can be seen in Fig. 1. $A B C B 1$ genotypes had the following $\mathrm{C}_{0} /$ dose ratios (mean (SD)): 78 (53) for C/C, 142 (104) for C/T and 103 (66) for T/T ( $p=0.015$ for $\mathrm{C} / \mathrm{C}$ v. $\mathrm{C} / \mathrm{T}$ and $p=0.347$ for $\mathrm{C} / \mathrm{C}$ v. T/T). The mean (SD) total daily dose per $A B C B 1$ genotype was $6(0.09) \mathrm{mg} / \mathrm{kg}, 3(0.05) \mathrm{mg} / \mathrm{kg}$ and $5(0.07)$ $\mathrm{mg} / \mathrm{kg}$ for $\mathrm{C} / \mathrm{C}, \mathrm{C} / \mathrm{T}$ and $\mathrm{T} / \mathrm{T}$, respectively.

Fig. 1 demonstrates the $\mathrm{C}_{0}$ /dose for tacrolimus by genotype during the study period, while Figs 2 and 3 demonstrate the effect of CYP3A5 and $A B C B 1$ genotype on tacrolimus $\mathrm{C}_{0} /$ dose ratios per participant, respectively.

\section{IPV during the study period}

Tacrolimus $\mathrm{C}_{0}$ varied among individual transplant recipients. Fig. 4 shows tacrolimus levels for each individual in the cohort over the four study quarters.

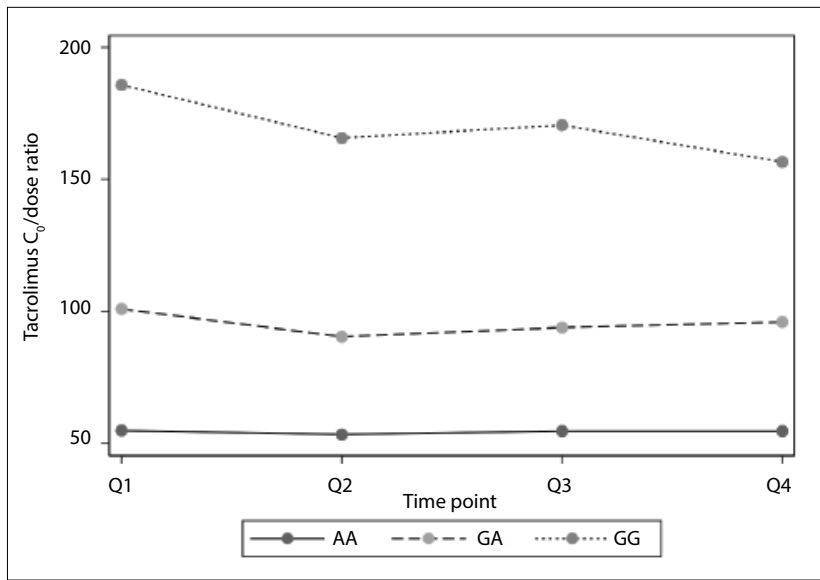

Fig. 1. Effect of $\mathrm{CYP} 3 \mathrm{~A} 5$ on $\mathrm{C}_{0}$ /dose ratio during study period. (CYP3A5 = cytochrome P-450 3A5 gene; $C_{0}=$ predose trough concentration; $Q=$ quarter.)



Fig. 2. Effect of CYP3A5 on tacrolimus $C_{0}$ /dose ratio in the study population. (CYP3A5 = cytochrome P-450 3A5 gene; $C_{0}=$ predose trough concentration.)
Fig. 5 shows the distribution of tacrolimus IPV in the study cohort during the study period. Figs 6 and 7 show IPV by genotype and ethnicity, respectively. IPV was divided into two groups using the median (interquartile range) IPV of $14.4 \%(10.5$ - 19.0) as a cut-

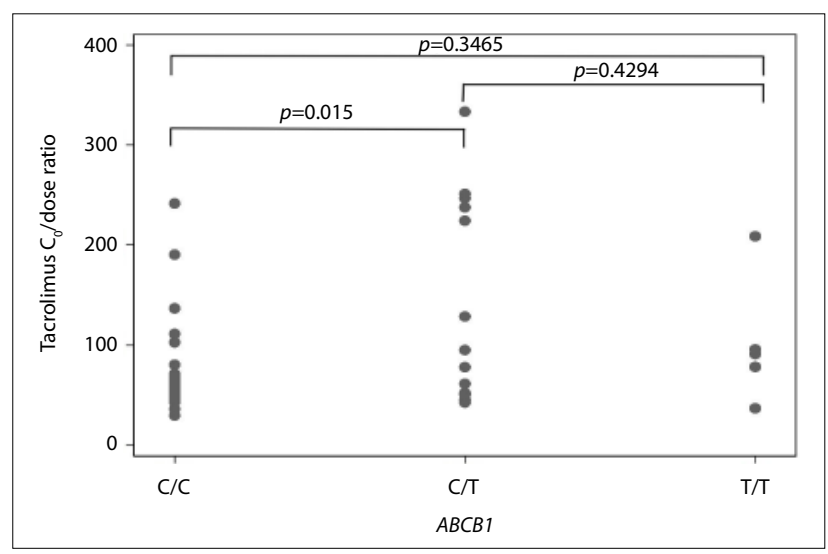

Fig. 3. Effect of $\mathrm{ABCB} 1$ on tacrolimus $C_{0} /$ dose ratio. $(\mathrm{ABCB} 1=A T P$-binding cassette subfamily B member 1 gene; $C_{0}=$ predose trough concentration.)

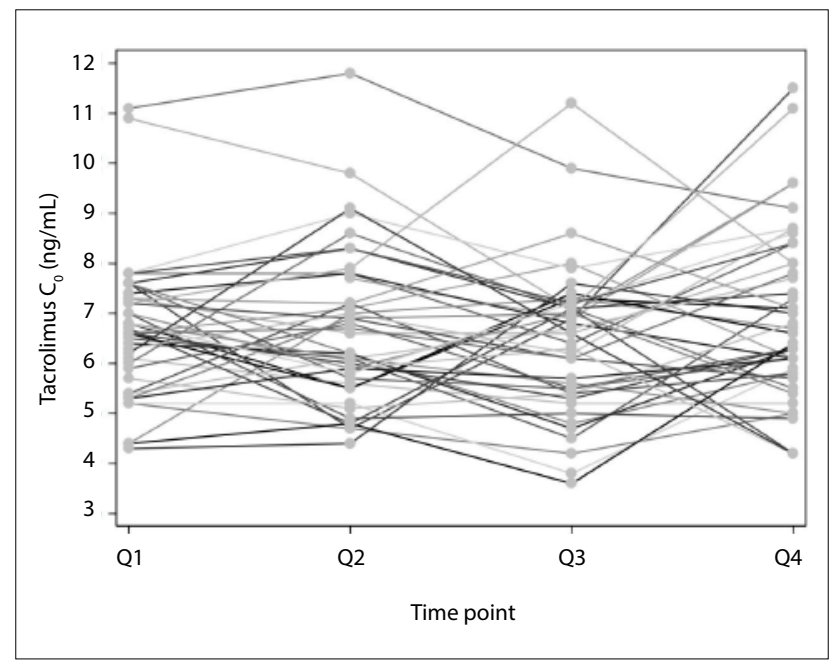

Fig. 4. Tacrolimus $C_{0}$ per patient over the study period. $\left(C_{0}=\right.$ predose trough concentration; $Q=$ quarter.)

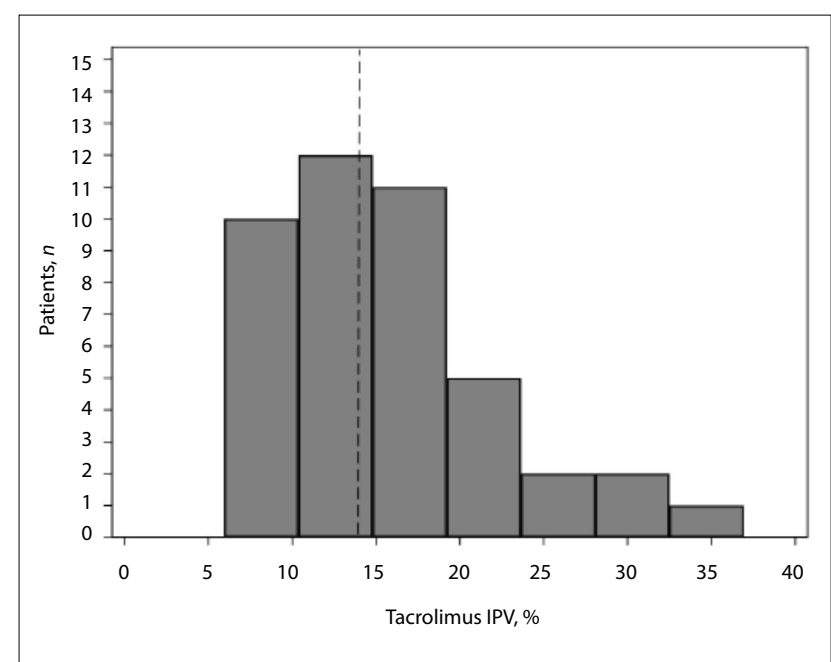

Fig. 5. Tacrolimus IPV among study participants over the study period $(\mathrm{N}=39)$. The median $(14.4 \%)$ is shown by the dotted line. (IPV = intrapatient variability.) 
off. IPV $\geq 14.4 \%$ was classified as high and $<14.4 \%$ as low. CYP3A5 expressors $\left({ }^{*} 1 /{ }^{*} 1+{ }^{*} 1 /{ }^{*} 3, n=28\right)$ had a lower IPV than CYP3A5 non-expressors $\left({ }^{*} 3{ }^{*} 3, n=11\right)$ with a mean (SD) IPV of $14.2 \%(6.6)$ v. $18.1 \%(7.5)$, respectively ( $p=0.125)$. Similarly, white participants had a higher IPV than those of black African and mixed ancestry $(p=0.041)$. Creatinine did not differ between high- and low-IPV groups $(p=0.757)$.

\section{Discussion}

This was an observational study examining tacrolimus $\mathrm{C}_{0}$ in stable renal transplant recipients attending a transplant clinic in Port Elizabeth, SA. Patients in the immediate post-transplant period were excluded because variations in tacrolimus levels often occur due to drug interactions such as high prednisone exposure, fluid shifts, and individual physician preferences to obtain therapeutic $\mathrm{C}_{0}{ }^{\left[{ }^{[9]}\right.}$

Over time, the mean tacrolimus $\mathrm{C}_{0}$ and dose did not change among the different genotypes studied. There was a slight rise in serum creatinine over the study period, but eGFR remained unchanged.

In this cohort, CYP3A5 expression varied markedly by ethnic group. Black African participants were much more likely to be CYP $3 A 5^{*} 1 /{ }^{*} 1$ and ${ }^{*} 1 /{ }^{*} 3$ carriers reflecting full or partial expression of CYP3A5 compared with white participants. Conversely, no black African participant was a CYP $3 A 5$ non-expressor $\left(C Y P 3 A 5^{*} 3 /{ }^{*} 3\right)$, while $88 \%$ of white participants were homozygous CYP3A5 nonexpressors, with none having normal expression of CYP3A5. Black African participants required a 2.1-fold higher dose to maintain therapeutic tacrolimus $\mathrm{C}_{0}$ compared with white participants. This is consistent with a previous study by Macphee et al ${ }^{[14]}$ Previous studies have also shown that white patients were more likely than black patients to present with $C Y P 3 A 5^{*} 3 /{ }^{*} 3$ genotypes. ${ }^{[24,25]}$ Haufroid et al. ${ }^{[23]}$ also demonstrated an allele effect of $C Y P 3 A 5^{*} 1 /{ }^{*} 1$, with a 2.3 -fold increase in daily dose requirements to maintain therapeutic tacrolimus $\mathrm{C}_{0}$ compared with $C Y P 3 A 5 * 3 / 3$.

The dose of tacrolimus required to achieve similar tacrolimus $\mathrm{C}_{0}$ was clearly affected by CYP3A5 genotype. Participants with the CYP3A5*3/*3 non-expressor genotype achieved over three times the tacrolimus $\mathrm{C}_{0} /$ dose ratio compared with those with normal expression $\left(C Y P 3 A 5^{*} 1 /{ }^{*} 1\right)$. Similarly, participants with the $C Y P 3 A 5^{\star} 1{ }^{*} 1$ genotype required a twofold increase in tacrolimus dose compared with those with the $C Y P 3 A 5^{*} 3{ }^{*} 3$ genotype in order to maintain therapeutic tacrolimus $\mathrm{C}_{0}$. This finding has major economic implications for SA, where until recently no cheaper generic formulations of tacrolimus have been available and where tacrolimus drug costs form a substantial part of the cost of transplantation. ${ }^{[4,26]}$

Participants of mixed ancestry had more variable expression of CYP3A5 than black Africans or whites. Black African and white ethnicity therefore appear to be a good proxy for CYP3A5 expression and non-expression, respectively, and could potentially allow reasonable prediction of dosing requirements in these population groups, while CYP3A5 genotyping could be reserved for patients of mixed ancestry, among whom there is a much wider spread in enzyme expression. Accurate prediction of dosing through this combination of ethnic profiling and genotyping could both be cost-effective and lead to improved graft outcomes by rapidly achieving appropriate tacrolimus $\mathrm{C}_{0}$, although further prospective studies would be needed to confirm this. In a recently published randomised controlled trial of pharmacogenetic adaptation of the tacrolimus starting dose according to CYP3A5 expression, genotyping did not lead to a higher percentage of participants reaching the desired outcome compared with the standard weight-based dose, and did not improve clinical outcomes. ${ }^{[25]}$ However, the ethnic distribution in that study was markedly skewed towards white patients (78\%), among whom non-expressor status is much more common and likely to lessen the effect of pharmacogenetic adaptation. In our cohort, $72 \%$ of participants were CYP3A5 expressors or partial expressors. In another study, $C Y P 3 A 5^{\star} 1 /{ }^{\star} 1$ genotype carriers were found to have more rejection episodes than heterozygous carriers $\left(C Y P 3 A 5^{\star} 11^{*} 3\right)$ and homozygous non-expressor genotype carriers $\left(C Y P 3 A 5^{*} 3{ }^{*} 3\right) .{ }^{[27]}$ Studies with a more equal ethnic distribution are needed to further assess genotype-based dosing. Similar studies by Thervet et al. ${ }^{[28]}$ and Shuker et al. ${ }^{[25]}$ showed that genotype-based dosing was associated with fewer dose modifications and a shorter time to reach the target tacrolimus $\mathrm{C}_{0}$. However, genotype-based dosing did not improve clinical outcomes. ${ }^{[25,28]}$

Black African participants predominantly expressed the $A B C B 1$ $\mathrm{C} / \mathrm{C}$ and $\mathrm{C} / \mathrm{T}$ genotypes, with no expression of the $\mathrm{T} / \mathrm{T}$ genotype. However, overall expression of the $A B C B 1$ genotype was more evenly distributed among the different ethnic groups than that of CYP3A5, and there was no clear polarising effect of ethnicity on $A B C B 1$ expression. There was a decrease in the achieved tacrolimus $\mathrm{C}_{0} /$ dose ratio among participants carrying the $\mathrm{C} / \mathrm{C}$ genotype compared with $\mathrm{C} / \mathrm{T}$ and $\mathrm{T} / \mathrm{T}$. This is probably due to increased expression of P-gp, which reduces net absorption of tacrolimus at the intestinal level. These findings are also consistent with those of Helal et al., ${ }^{[1]}$ who demonstrated that participants expressing the $\mathrm{C} / \mathrm{C}$ genotype had a lower tacrolimus $\mathrm{C}_{0}$ /dose ratio compared with other genotypes of $A B C B 1$. Previous studies have not consistently demonstrated an effect of the $A B C B 1$ SNP on tacrolimus $\mathrm{C}_{0} /$ dosing.

Variability of tacrolimus $\mathrm{C}_{0}$ strongly correlates with a negative effect on graft outcomes. ${ }^{[9,10]}$ Studies have shown that a tacrolimus SD of $\mathrm{C}_{0}$ of $>2$ is associated with increased late acute rejection, and that patients with higher IPV have a 1.4 times increased risk of allograft injury or rejection. ${ }^{[29]}$ High variability in tacrolimus $\mathrm{C}_{0}$ has also been shown to correlate with poorer overall graft function. ${ }^{[10,13,29,30]}$ Although most of our study participants had therapeutic tacrolimus $\mathrm{C}_{0}$, significant intraand IPV was present in $14.4 \%$ (see Fig. 6). This is somewhat lower than the figure reported by Shuker et al. ${ }^{[13]}$ in their large study of 808 renal transplant recipients, in which the median IPV was $16.2 \%$, and may reflect the high proportion of CYP3A5 expressors in our study $(72 \%)$. In an excellent review of the subject, ${ }^{[13]}$ these authors noted that CYP3A5 non-expression was associated with increased tacrolimus IPV in one small Korean study where the expressor genotype was present in $55 \%$ of the cohort, ${ }^{[31]}$ but not in three larger studies, ${ }^{[29,32,33]}$ where the prevalence of the CYP3A5 expressor genotype in the population studied was very much lower at between $9 \%$ and $45 \%$. Similar to the Korean study, the prevalence of the CYP3A5 expressor genotype in our cohort was much higher at $72 \%$ and is comparable to the previously reported allele frequency of $85 \%$ in healthy SA black Africans. ${ }^{[34]}$ The increase in IPV of tacrolimus $\mathrm{C}_{0}$ in CYP3A5 nonexpressors has been postulated to be due to their increased reliance on CYP3A4 for tacrolimus metabolism and the fact that CYP3A4 is more prone to induction and inhibition. ${ }^{[35]}$ Similarly, CYP3A5 non-expressors were shown to be more prone to the inhibitory effects of fluconazole on tacrolimus metabolism owing to the fact that fluconazole relies predominantly on CYP3A4 for metabolism. ${ }^{[36]}$ Knowing the CYP3A5 expressor status of an individual therefore also has relevance in determining the risk of drug-drug interactions in transplant recipients, who not infrequently require treatment with drugs that interfere with CYP450 metabolism.

CYP3A5 SNPs only explain 40 - 50\% of tacrolimus variability among patients. ${ }^{[1]}$ Other factors such as food ingestion, type of assay used, diarrhoea, drug-drug interactions, haematocrit and compliance issues may also play a role. ${ }^{[13,24]}$ Non-adherence to tacrolimus is 


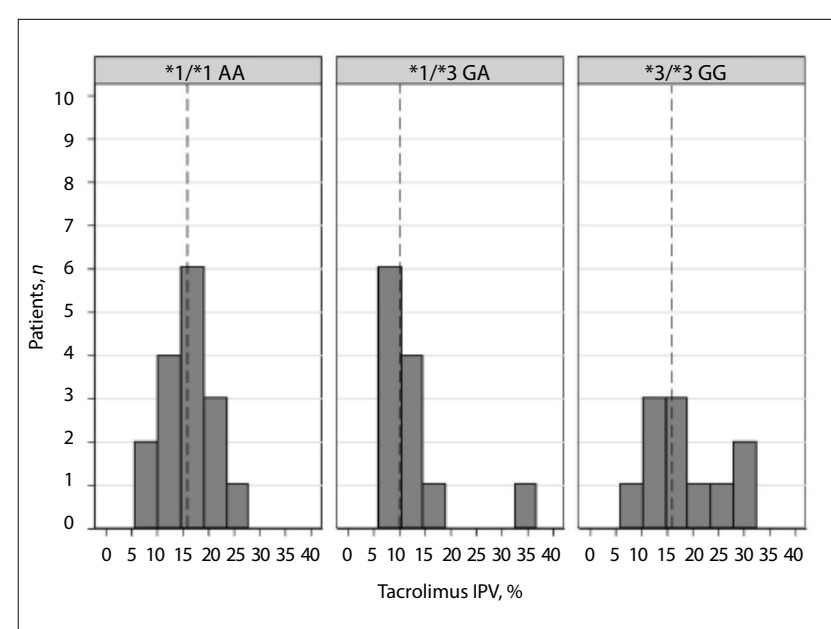

Fig. 6. Effect of the CYP3A5 genotype on tacrolimus IPV. The median is shown by the dotted line. (CYP3A5 = cytochrome P-450 3A5 gene; IPV = intra-patient variability.)

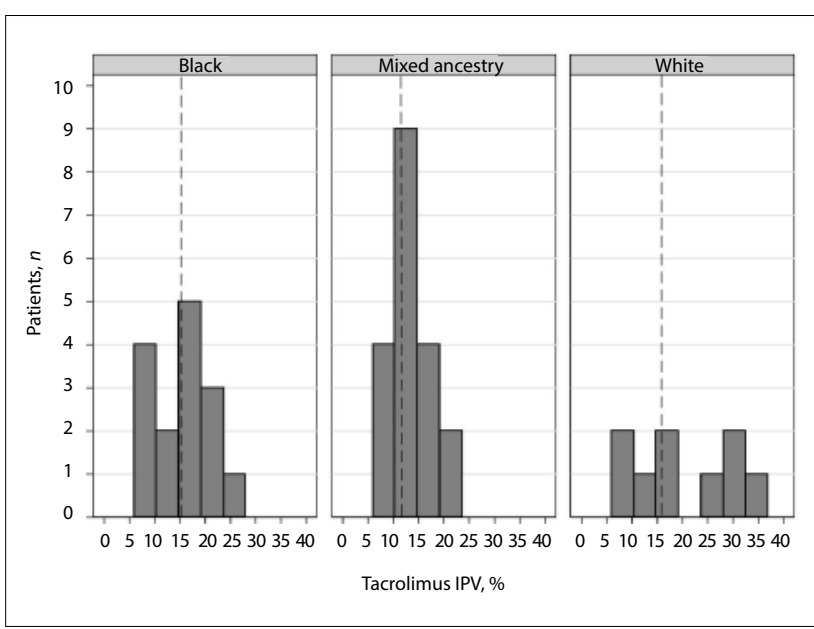

Fig. 7. Tacrolimus IPV for the different ethnic groups studied. The median is shown by the dotted line. (IPV = intra-patient variability.)

probably the most common reason for tacrolimus inter- and IPV. All our study participants reported good adherence during the 1-year study period, with non-adherence being assessed clinically if the tacrolimus $\mathrm{C}_{0}$ fell out of the therapeutic range.

\section{Study limitations}

The present study has several limitations. The fact that it was conducted at a single centre and had a relatively small sample size compared with other studies may affect some aspects of the findings, and translation of our results may not be feasible for other centres. The duration of follow-up (1 year) was short compared with other studies, where durations were up to 10 years, and longer follow-up may further describe the gene effect on creatinine over time. Other enzymes that may explain tacrolimus variability, such as CYP2C8, POR and the nuclear receptor PPAR- $\alpha$, were not investigated owing to cost limitations. Linkage disequilibrium may be present among genes. Gene interactions may play an important role, and further study is needed to assess this effect.

\section{Conclusions}

This study confirms the previously described effects of CYP $3 A 5$ SNPs on tacrolimus $\mathrm{C}_{0}$ and dosing requirements. Furthermore, it appears to support the notion that CYP3A5 non-expression may be associated with increased IPV in tacrolimus $\mathrm{C}_{0}$. With the exception of patients of mixed ancestry, black African and white ethnicity should serve as a proxy for CYP $3 A 5$ expression and nonexpression, respectively, in SA patients, necessitating higher and lower starting doses of tacrolimus, respectively, prior to therapeutic drug level monitoring being available. While a genotype-based tacrolimus dosing algorithm could still be beneficial in predicting an appropriate starting or switching dose of tacrolimus in a multiethnic population such as ours, this could be restricted to patients of mixed ancestry in order to reduce costs. Finally, the high frequency of the $C Y P 3 A 5^{*} 1 /{ }^{*} 1$ and ${ }^{*} 1 /{ }^{*} 3$ expressor genotype has important cost implications for the provision of tacrolimus-based immunosuppression in SA. Since tacrolimus is also used in the treatment of various autoimmune diseases, this may well have wider applicability outside of transplantation medicine.

Declaration. This publication was part of the requirements for WKM's MMed (Internal Medicine).

Acknowledgements. The authors are grateful to all the nursing staff in the Livingstone Hospital renal unit, and in particular Sister Lucille Claasen. We thank Dr Naomi Hendricks for assistance with blood sample and data collection and Dr Teun van Gelder for his kind appraisal of the manuscript. Author contributions. WKM, lead investigator and MMed student: responsible for protocol development, data collection and write-up of thesis. RF, consultant nephrologist: supervisor for MMed project. Provided expert input with regard to kidney transplants and immunosuppression. $\mathrm{CD}$, Professor of Pharmacogenomics, University of Cape Town: co-supervisor for MMed project. Provided expert input into pharmacogenomics including DNA extraction and genotyping of cytochrome enzymes. KM, statistician: provided expert input into statistical analysis of results obtained from the study. JE, consultant nephrologist: co-supervisor for MMed project. ZB, consultant nephrologist, University of Cape Town: expert opinion. DM, pharmacogenomics, University of Cape Town: assisted with DNA extraction and genotyping of blood samples.

Funding. This study was supported by educational grants from the Discovery Foundation and Amgen Pharmaceuticals.

Conflicts of interest. None.

1. Tang JT, Andrews LM, van Gelder T, et al. Pharmacogenetic aspects of the use of tacrolimus in rena transplantation: Recent developments and ethnic considerations. Expert Opin Drug Metab Toxico 2016;12(5):555-565. https://doi.org/10.1517/17425255.2016.1170808

2. Knoll GA, Bell RC. Tacrolimus versus cyclosporin for immunosuppression in renal transplantation: Meta-analysis of randomised trials. BMJ 1999;318(7191):1104-1107. https://doi.org/10.1136/ bmj.318.7191.1104

3. Margreiter R. Efficacy and safety of tacrolimus compared with ciclosporin microemulsion in renal transplantation: A randomised multicentre study. Lancet 2002;359(9308):741-746. https://doi. org/10.1016/S0140-6736(02)07875-3

4. Muller E. Organ donation and transplantation in South Africa. Continuing Medical Education 2013;31(6):220-222.

2013;31(6):220-222.
Atkins RC. The epidemiology of chronic kidney disease. Kidney Int 2005;94:S14-S18. https://doi. Atkins RC. The epidemiology of ch.
org/10.1111/j.1523-1755.2005.09403.x

6. Thervet E, Anglicheau D, King B, et al. Impact of cytochrome P450 3A5 genetic polymorphism on tacrolimus doses and concentration-to-dose ratio in renal transplant recipients. Transplantation 2003;76(8):1233-1235. https://doi.org/10.1097/01.TP.0000090753.99170.89

7. Venkataramanan R, Swaminathan A, Prasad T, et al. Clinical pharmacokinetics of tacrolimus. Clin Pharmacokinet 1995;29(6):404-430. https://doi.org/10.2165/00003088-199529060-00003

8. Shuker $\mathrm{N}$, Shuker L, van Rosmalen J, et al. A high intrapatient variability in tacrolimus exposure is associated with poor long-term outcome of kidney transplantation. Transplant Int 2016;29(11):11581167. https://doi.org/10.1111/tri.12798

9. Sapir-Pichhadze R, Wang Y, Famure O, Li Y, Kim SJ. Time-dependent variability in tacrolimus trough blood levels is a risk factor for late kidney transplant failure. Kidney Int 2014;85(6):1404-1411. https:// doi.org/10.1038/ki.2013.465

10. Whalen HR, Glen JA, Harkins V, et al. High intrapatient tacrolimus variability is associated with worse outcomes in renal transplantation using a low-dose tacrolimus immunosuppressive regime. worse outcomes in renal transplantation using a low-dose tacrolimus immunos
Transplantation 2017;101(2):430-436. https://doi.org/10.1097/TP.0000000000001129

11. Staatz C, Taylor P, Tett S. Low tacrolimus concentrations and increased risk of early acute rejection in adult renal transplantation. Nephrol Dial Transplant 2001;16(9):1905-1909. https://doi.org/10.1093/ ndt/16.9.1905 
12. Böttiger Y, Brattström C, Tyden G, Säwe J, Groth C. Tacrolimus whole blood concentrations correlate closely to side-effects in renal transplant recipients. Br J Clin Pharmacol 1999;48(3):445-448. https://doi closely to side-effects in renal transplant
org/10.1046/j.1365-2125.1999.00007.x

13. Shuker N, van Gelder T, Hesselink DA. Intra-patient variability in tacrolimus exposure: Causes consequences for clinical management. Transplant Rev 2015;29(2):78-84. https://doi.org/10.1016/j. consequences

14. Macphee IAM, Fredericks S, Tai T, et al. Tacrolimus pharmacogenetics: Polymorphisms associated with expression of cytochrome p4503A5 and p-glycoprotein correlate with dose requirement. Transplantatio 2002;74(11):1486-1489. https://doi.org/10.1097/00007890-200212150-00002

15. Mourad M, Wallemacq P, de Meyer M, et al. The influence of genetic polymorphisms of cytochrome P450 $3 \mathrm{~A} 5$ and $A B C B 1$ on starting dose- and weight-standardized tacrolimus trough concentrations afte kidney transplantation in relation to renal function. Clin Chem Lab Med 2006;44(10):1192-1198. https:// doi.org/10.1515/CCLM.2006.229

16. Haufroid V, Mourad M, van Kerckhove V, et al. The effect of CYP3A5 and MDRI ( $A B C B 1)$ polymorphisms on cyclosporine and tacrolimus dose requirements and trough blood levels in stable renal transplant patients. Pharmacogenetics 2004;14(3):147-154. https://doi.org/10.1097/00008571-200403000-00002

17. Kim I-W, Moon YJ, Ji E, et al. Clinical and genetic factors affecting tacrolimus trough levels and drugrelated outcomes in Korean kidney transplant recipients. Eur J Clin Pharmacol 2012;68(5):657-669. related outcomes in Korean kidney transp

18. Li Y, Yan L, Shi Y, Bai Y, Tang J, Wang L. CYP3A5 and $A B C B 1$ genotype influence tacrolimus and sirolimus pharmacokinetics in renal transplant recipients. SpringerPlus 2015;4(1):1-6. https://doi. sirolimus pharmacokinetics in
org/10.1186/s40064-015-1425-5

19. Lunde I, Bremer S, Midtvedt K, et al. The influence of CYP3A, PPARA, and POR genetic variants on the pharmacokinetics of tacrolimus and cyclosporine in renal transplant recipients. Eur J Clin Pharmaco 2014;70(6):685-693. https://doi.org/10.1007/s00228-014-1656-3

20. Tada $\mathrm{H}$, Tsuchiya N, Satoh S, et al. Impact of CYP3A5 and MDR1(ABCB1) C3435T polymorphisms on the pharmacokinetics of tacrolimus in renal transplant recipients. Transplant Proc 2005;37(4):1730-1732. https://doi.org/10.1016/j.transproceed.2005.02.073

21. Helal M, Obada M, Elrazek WA, Safan M, El-Hakim TA, El-Said H. Effect of $A B C B 1(3435 \mathrm{C}>\mathrm{T})$ and CYP3A5 $(6986 \mathrm{~A}>\mathrm{G})$ genes polymorphism on tacrolimus concentrations and dosage requirements in liver transplant patients. Egypt J Med Hum Genet 2017;18(3):261-268.

22. Rong G, Jing L, Deng-Qing L, Hong-Shan Z, Shai-Hong Z. Influence of CYP3A5 and MDR1(ABCB1) polymorphisms on the pharmacokinetics of tacrolimus in Chinese renal transplant recipients. Transplant polymorphisms on the pharmacokinetics of tacrolimus in Chinese renal transpla
Proc 2010;42(9):3455-3458. https://doi.org/10.1016/j.transproceed.2010.08.063

23. Haufroid V, Wallemacq P, VanKerckhove V, Elens L, de Meyer M. CYP3A5 and $A B C B 1$ polymorphisms and tacrolimus pharmacokinetics in renal transplant candidates: Guidelines from an experimental study. and tacrolimus pharmacokinetics in renal transplant candidates: Guidelines from an exper

24. Roy J-N, Lajoie J, Zijenah LS, et al. CYP3A5 genetic polymorphisms in different ethnic populations. Drug Metab Dispos 2005;33(7):884-887. https://doi.org/10.1124/dmd.105.003822
25. Shuker N, Bouamar R, Schaik RHN, et al. A randomized controlled trial comparing the efficacy of CYP3A5 genotype-based with body-weight-based tacrolimus dosing after living donor kidney transplantation. Am J Transplant 2016;16(7):2085-2096. https://doi.org/10.1111/ajt.13691

26. Venkat VL, Nick TG, Wang Y, Bucuvalas JC. An objective measure to identify pediatric liver transplant recipients at risk for late allograft rejection related to non-adherence. Pediatr Transplant 2008;12(1):67recipients at risk for late allograft rejection related to
72. https://doi.org/10.1111/j.1399-3046.2007.00794.x

27. Quteineh L, Verstuyft C, Furlan V, et al. Influence of CYP3A5 genetic polymorphism on tacrolimus daily dose requirements and acute rejection in renal graft recipients. Basic Clin Pharmacol Toxicol 2008;103(6):546-552. https://doi.org/10.1111/j.1742-7843.2008.00327.x

28. Thervet $\mathrm{E}$, Loriot MA, Barbier $\mathrm{S}$, et al. Optimization of initial tacrolimus dose using pharmacogenetic testing. Clin Pharmacol Ther 2010;87(6):721-726. https://doi.org/10.1038/clpt.2010.17

29. Van Schaik RH, van der Heiden IP, van den Anker IN, Lindemans J. CYP3A5 variant allele frequencies in Dutch Caucasians. Clin Chem 2002;48(10):1668-1671

30. Rodrigo E, Segundo DS, Fernández-Fresnedo G, et al. Within-patient variability in tacrolimus blood levels predicts kidney graft loss and donor-specific antibody development. Transplantation 2016;100(11):2479-2485. https://doi.org/10.1097/TP.0000000000001040

31. Yong Chung J, Jung Lee Y, Bok Jang S, Ahyoung Lim L, Soo Park M, Hwan Kim K. CYP3A5*3 genotype associated with intrasubject pharmacokinetic variation toward tacrolimus in bioequivalence study. Ther Drug Monit 2010;32(1):67-72. https://doi.org/10.1097/FTD.0b013e3181c49a4c

32. Pashaee N, Bouamar R, Hesselink DA, et al. CYP3A5 genotype is not related to the intrapatient variability of tacrolimus clearance. Ther Drug Monit 2011;33(3):369-371. https://doi.org/10.1097/ ETD.0b013e31821a7aa3

33. Spierings N, Holt DW, MacPhee IAM. CYP3A5 genotype had no impact on intrapatient variability of tacrolimus clearance in renal transplant recipients. Ther Drug Monit 2013;35(3):328-331. https:// doi.org/10.1097/FTD.0b013e318289644C

34. Dandara C, Lombard Z, du Plooy I, McLellan T, Norris SA, Ramsay M. Genetic variants in CYP $(-1 A 2,-2 C 9,-2 C 19,-3 A 4$ and $-3 A 5), V K O R C 1$ and $A B C B 1$ genes in a black South African population: A window into diversity. Pharmacogenomics 2011;12(12):1663-1670. https://doi. org/10.2217/pgs.11.106

35. Floyd MD, Gervasini G, Masica AL, et al. Genotype-phenotype associations for common CYP3A4 and CYP3A5 variants in the basal and induced metabolism of midazolam in European- and AfricanAmerican men and women. Pharmacogenet Genomics 2003;13(10):595-606.

36. Kuypers DR, de Jonge $\mathrm{H}$, Naesens $M$, Vanrenterghem Y. Effects of CYP3A5 and MDR1 single nucleotide polymorphisms on drug interactions between tacrolimus and fluconazole in renal allograft recipients. Pharmacogenet Genomics 2008;18(10):861-868. https://doi.org/10.1097/FPC.0b013e328307c26e

Accepted 3 July 2019 